\title{
The Effect of Age on Thoroughbred Racing Performance
}

\author{
Marshall GRAMM $^{1^{*}}$ and Ryne MARKSTEINER ${ }^{2}$ \\ ${ }^{1}$ Department of Economics and Business, Rhodes College, 2000 N. Parkway, Memphis, TN 38112-1690, \\ ${ }^{2}$ Department of Economics, University of Wisconsin, William H. Sewell Social Science Building, 1180 \\ Observatory Drive, Madison, WI 53706-1393, USA
}

Using a dataset of 274 male Thoroughbred racehorses in the United States, we study the effect of age on racing performance. Beyer speed figures, which are uniform measures of racing performance across distance and racing surface, are utilized in this study. A system of equations is estimated to determine quadratic improvement and decline in racing performance. We find that a typical horse's peak racing age is 4.45 years. The rate of improvement from age 2 to $4 \frac{1}{2}$ is greater than the rate of decline after age $4 \frac{1}{2}$. A typical horse will improve by 10 (horse) lengths in sprints (less than 1 mile) and 15 lengths in routes (one mile or greater) from age 2 to 41/2. Over the next five years the typical decline is 6 lengths for sprints and $91 / 2$ lengths for routes.

Key words: age, peak performance, racing, speed figures, Thoroughbred
J. Equine Sci.

Vol. 21, No. 4

pp. 73-78, 2010
Thoroughbred racehorses compete at tracks across the country nearly every day of the year. Northern hemisphere racehorses are given a universal birth date of January 1st of the year in which they are born. Horses generally compete in their age cohort through the spring of their three-year-old year. It is perceived as advantageous to have a horse born as close as possible to January 1st since the horse will be slightly older and therefore more mature than his or her peers.

When thoroughbreds begin racing outside their age cohort, they are exposed to competition with much more age variation than the few months separating racehorses of the same universal age. Horses may race until they are well over ten years old, at which point they will still compete with some horses as young as age three or four. This broad range of prospective competition motivates inquiry into the nature of aging among thoroughbred racehorses.

This study focuses on the effect of age on a racehorse's performance. There have been multiple studies on the effect of human aging in various competitive endeavors. Fair $[6,7]$ looks at the peak age for performance and rates of decline in competitive

This article was accepted September 17, 2010

*Corresponding author. e-mail: gramm@rhodes.edu swimming, track and field, and chess. Fair [8] and Bradbury [4] analyze the effect of aging on baseball performance. Over and Thomas [13] and Baker, Deakin, Horton, and Pearce [1] study the effect of aging on golf. Studies on the growth rates of thoroughbreds have concentrated on physiological development $[9,10,11,15]$. Brown-Douglas, Pagan, and Stromberg [5] study the physical development of young horses and how it translates into future racing performance. They focus exclusively on weight and height of horses as foals, sucklings, weanlings, and yearlings to project future success. Sobczyńska [14] uses survival time analysis to quantify factors that affect the length of a racing career. More [12] and Bailey, Reid, Hodgson, and Rose [3] look at factors that affect the length of racing careers for Australian racehorses.

The purpose of this study is to find the peak age for a Thoroughbred's racing performance and determine the rates at which a horse's speed increases to its peak and declines past it. Beyer Speed Figures are used to measure racing performance. Andrew Beyer popularized speed figures in his 1975 book "Picking Winners", and they were first published in the Daily Racing Form in 1992. Speed figures are a way to quantify how fast a particular race is run by normalizing the distance of the race and taking into account the inherent speed of the racetrack on a given day. Speed 
Table 1. Speed Figures

\begin{tabular}{ccccc}
\hline \multicolumn{2}{c}{$3 / 4$ mile } & & \multicolumn{2}{c}{$11 / 8$ mile } \\
\cline { 5 - 5 } Time & Speed Figure & & Time & Speed Figure \\
\hline $1: 08$ & 135 & & $1: 47$ & 132 \\
$1: 09$ & 120 & & $1: 48$ & 122 \\
$1: 10$ & 106 & & $1: 49$ & 113 \\
$1: 11$ & 92 & & $1: 50$ & 104 \\
$1: 12$ & 78 & $1: 51$ & 95 \\
$1: 13$ & 64 & $1: 52$ & 86 \\
$1: 14$ & 51 & $1: 53$ & 77 \\
$1: 15$ & 37 & $1: 54$ & 68 \\
$1: 16$ & 24 & $1: 55$ & 60 \\
& & $1: 56$ & 51 \\
& & $1: 57$ & 42 \\
\hline
\end{tabular}

figures do not account for weighted carried. Once a race is rated, every horse in the race then receives a speed figure based on how many lengths behind the leader he finished. Table 1 [2] shows speed figures translated from the raw times in 6 furlong $(3 / 4$ mile; raced around one turn) and 9 furlong ( $11 / 8$ mile) races. On a typical track a 1:12 for 6 furlongs is almost equivalent to a 1:53 for 9 furlongs (78 and 77 speed figure respectively). Adjustments are made to account for how quick races were run on a particular day.

Table 2 [2] is the conversion for beaten horse lengths for the two distances. A horse beaten by two lengths in a 6 furlong sprint will receive a speed figure 5 points lower than the winner.

A high caliber racehorse that competes in the top races (called stakes races) will run between a 100 and 120. A horse's speed figures may vary widely over the course of a career. The average speed figure for the top Breeders' Cup Juvenile, the top U.S. race for male twoyear-olds (run in the fall), the Kentucky Derby, the top U.S. race for male three-year-olds (run in the spring), and the Breeders' Cup Classic, one of the top U.S. races with no age restrictions (run in the fall), are 100, 109 , and 117 , respectively, indicating substantial improvement with age. The differences between the speed figures indicate that for a $1 \frac{1 / 4}{4}$ mile race, the typical Kentucky Derby winner would finish six (horse) lengths ahead of the typical Breeders' Cup Juvenile and $5^{1 / 2}$ lengths behind the typical Breeders' Cup Classic winner.

\section{Materials and Methods}

The dataset is composed of 274 male horses that are
Table 2. Beaten Lengths Adjustments

\begin{tabular}{ccc}
\hline Margin & $3 / 4$ mile & $11 / 8$ mile \\
\hline 0.5 & 1 & 1 \\
1 & 2 & 2 \\
2 & 5 & 3 \\
3 & 7 & 5 \\
4 & 10 & 6 \\
5 & 12 & 8 \\
6 & 15 & 9 \\
7 & 17 & 11 \\
8 & 20 & 13 \\
9 & 22 & 14 \\
10 & 25 & 16 \\
\hline
\end{tabular}

at least six years old and have made at least 45 starts. These two requirements yield horses with a sufficiently extensive career for an analysis of peak performance. A potential sample selection problem exists because the top male horses often are retired to be breeding stallions well before they satisfy these cutoffs. A stallion can be bred to an excess of one hundred mares a year. Therefore, very few male horses are retired to stallion duty, and most have no breeding value and are eventually castrated (called geldings). The horses that meet the criteria for the dataset have no residual breeding value and the majority of them are geldings. Likewise, many female horses have breeding value and therefore are more likely to have shorter racing careers. For this reason we focused exclusively on older male horses. Another potential issue is that in the U.S. many of the most prestigious races are restricted to younger horses. The Triple Crown, consisting of the Kentucky Derby, Preakness, and Belmont, is run in the spring and restricted to three-year-olds. Of the 14 races of the Breeders' Cup, four are for two-year-olds. A precocious horse is rewarded by the high purses in these agerestricted races and often ends up retiring early to stud. Therefore, a concern is whether horses that meet the criteria stipulated for the sample are an adequate representation of the male Thoroughbred population. If so, then the peak age and rate of incline and decline for the sample should be reasonable estimates for the entire population.

Summary statistics for the 274 horses in the sample are in Table 3. The age referred to throughout this paper is the horse's actual age rather than the age according to the uniform January 1st birthday. Cool $\mathrm{N}$ Collective, born March 22, 1997, is the oldest horse in the dataset at 12.4 years old when he ran at Suffolk 
Table 3. Summary Statistics for Horses

\begin{tabular}{lccc}
\hline Variable & Mean & Min & Max \\
\hline Starts & 65.1 & 45 & 121 \\
Age at last start & 8.0 & 4.7 & 12.4 \\
Wins & 9 & 1 & 23 \\
Earnings & $\$ 178,914$ & $\$ 28,699$ & $\$ 1,174,781$ \\
Avg Speed Figure & 59.1 & 31.0 & 88.7 \\
St Dev Speed Figure & 15.3 & 8.6 & 25.4 \\
Best Speed Figure & 84.5 & 50 & 108 \\
Avg Distance (furlongs) & 6.91 & 5.22 & 9.24 \\
\hline
\end{tabular}

Downs on September 5, 2009. Ten horses have started at least 100 times with ten-year-old Ww Conquistador running the most at 121 . More than $40 \%$ of the horses in the sample have won at least ten times. Ww Conquistador also has the most wins with a record of 23 wins in all. Multiple stakes winner Fort Prado is the only millionaire in the sample, and his 88.7 speed figure average is the highest for the dataset. Average earnings are $\$ 178,914$, and the overall mean speed figure is 59.1. Lower earning horses are typically retired from racing because the owner isn't able to cover variable costs (training expenses and veterinary bills) with purse money. Fly by Moonlight, an eightyear-old gelding with earnings of $\$ 170,354$ and an average speed figure of 57.8 , both very close to mean values for the dataset, ties for the highest speed figure in the sample. He earned a figure of 108 when he won by 11 lengths in November 2004. Orphan Brigade also earned a 108 in October 2005 but boasts an average speed figure of 83.2, well above average for the dataset. Average distance is measured in furlongs, and there are eight furlongs in a mile. Horses compete on three different surfaces: dirt, grass, and a synthetic allweather surface. Average race distance is 6.91 furlongs with $30 \%$ of races at 6 furlongs and fewer than $1 \%$ at the classic distance of $1 \frac{1 / 4}{4}$ mile or farther.

Two methods are used to analyze the effect of age on racing performance. The first is to group horses' races by age at the time of the race and compare the speed figure earned in that race at that age to the mean speed figure for that horse's entire career. A second method is to estimate a system of equations and solve for the age of peak performance.

Fair [8] develops a model for aging effects in baseball that is used here for race horses. The model assumes that horses have quadratic improvement up to the age of peak performance and experience a quadratic decline in racing ability past that age. The model for horse $i$ is:

$$
y_{i t}=\begin{aligned}
& \alpha_{1 i}+\beta_{1} x_{i t}+\gamma_{1} x^{2}{ }_{i t}+\varepsilon_{i t}, \quad x_{i t} \leq \delta \\
& \alpha_{2 i}+\beta_{2} x_{i t}+\gamma_{2} x^{2}{ }_{i t}+\varepsilon_{i t}, \quad x_{i t} \leq \delta
\end{aligned}
$$

where $y_{i t}$ is the speed figure at time $t, x$ is the age of the horse at time $t$, and $\delta$ is the age of peak performance for the sample. The two equations have the following constraints to ensure that they come together at $\delta$ with zero slope:

$$
\begin{aligned}
& \beta_{1}=-2 \gamma_{1} \delta \\
& \beta_{2}=-2 \gamma_{2} \delta \\
& \alpha_{2 i}=\alpha_{1 i}+\left(\gamma_{2}-\gamma_{1}\right) \delta^{2}
\end{aligned}
$$

To control for fixed effects, let $p_{j i t}$ be a horse specific dummy variable equal to 1 if $j=i$ and 0 otherwise. Imposing the constraints on equation (1) reduces the two equations to

$$
\begin{aligned}
& y_{i t}=\sum_{j=1}^{k} \alpha_{j} \mathrm{p}_{j i t}+\gamma_{1}\left[\left(\delta^{2}-2 \delta x_{i t}+x^{2}{ }_{i t}\right) d_{i t}\right]+\gamma_{2}\left[-\delta^{2} d_{i t}+\right. \\
& \left.\left(x^{2}{ }_{i}-2 \delta x_{i t}\right)\left(1-d_{i t}\right)\right]+\varepsilon_{i t}
\end{aligned}
$$

where $d_{i t}=1$ if $x_{i t} \leq \delta$ and 0 otherwise. To find the correct standard errors, this equation is estimated using non-linear least squares.

\section{Results and Discussion}

Table 4 groups horses into 25 categories based on age and shows the average difference between the speed figure a horse earned in a particular race and that horse's career mean speed figure. For example, 130 horses made 357 total starts when they were less than 21/2 years old. Speed figures for the horses running in these 357 races average 17.2 points or 1.14 standard deviations below their career mean speed figure (Diff and St Diff). This differential translates into seven lengths for a 6 furlong race. The speed figure difference is negative but smaller in size through age $3 \frac{1}{4}$ years. Every category between $3 \frac{1}{4}$ years and $6 \frac{1}{2}$ years has a positive difference, indicating that horses typically run faster than their career mean between these ages. The peak difference occurs between ages $4 \frac{1}{4}$ and $4 \frac{1}{2}$ when horses run 5 points faster than their career mean (two lengths faster for a 6 furlong sprint and three lengths faster for a 9 furlong route). Figure 1 provides a graphical representation of speed figure differences across age categories. Beyond age $63 / 4$ the speed figure differences are once again negative, because a typical horse is past his peak age and is consequently slowing down. Horses older than 9 years 
Table 4. Racing Performance and Distance by Age

\begin{tabular}{|c|c|c|c|c|c|c|c|c|}
\hline \multirow[b]{2}{*}{ Age } & \multirow[b]{2}{*}{ Starts } & \multirow[b]{2}{*}{ Starters } & \multicolumn{2}{|c|}{ Speed Figure } & \multirow[b]{2}{*}{$\%$ High SF } & \multirow[b]{2}{*}{ Highest SF } & \multicolumn{2}{|c|}{ Distance } \\
\hline & & & Diff & St Diff & & & $\overline{\text { Diff }}$ & St Diff \\
\hline$<2.5$ & 357 & 130 & -17.2 & -1.1 & $0.36 \%$ & 85 & -0.75 & -0.82 \\
\hline $2.5-2.75$ & 439 & 165 & -12.4 & -0.8 & $0.55 \%$ & 90 & -0.11 & -0.07 \\
\hline $2.75-3$ & 486 & 177 & -5.9 & -0.4 & $2.19 \%$ & 97 & 0.03 & 0.06 \\
\hline $3-3.25$ & 698 & 213 & -3.1 & -0.2 & $3.16 \%$ & 100 & 0.14 & 0.17 \\
\hline $3.25-3.5$ & 770 & 222 & 0.9 & 0.1 & $8.45 \%$ & 99 & 0.14 & 0.17 \\
\hline $3.5-3.75$ & 704 & 220 & 1.9 & 0.1 & $7.12 \%$ & 108 & 0.03 & 0.05 \\
\hline $3.75-4$ & 665 & 209 & 3.3 & 0.2 & $4.32 \%$ & 106 & 0.09 & 0.12 \\
\hline $4-4.25$ & 847 & 238 & 3.6 & 0.2 & $9.88 \%$ & 106 & 0.06 & 0.07 \\
\hline $4.25-4.5$ & 944 & 249 & 5.0 & 0.3 & $8.36 \%$ & 107 & 0.10 & 0.10 \\
\hline $4.5-4.75$ & 798 & 236 & 4.9 & 0.3 & $7.79 \%$ & 108 & 0.09 & 0.10 \\
\hline $4.75-5$ & 715 & 218 & 4.5 & 0.3 & $6.87 \%$ & 105 & 0.06 & 0.06 \\
\hline $5-5.25$ & 849 & 245 & 3.7 & 0.2 & $5.90 \%$ & 103 & -0.03 & -0.03 \\
\hline $5.25-5.5$ & 918 & 247 & 3.3 & 0.2 & $7.91 \%$ & 104 & 0.04 & 0.03 \\
\hline $5.5-5.75$ & 794 & 235 & 1.7 & 0.1 & $4.68 \%$ & 100 & 0.06 & 0.05 \\
\hline $5.75-6$ & 632 & 198 & 0.6 & 0.0 & $2.74 \%$ & 100 & 0.02 & -0.01 \\
\hline $6-6.25$ & 863 & 242 & 1.5 & 0.1 & $4.53 \%$ & 103 & -0.03 & -0.05 \\
\hline $6.25-6.5$ & 914 & 247 & 0.1 & 0.0 & $2.95 \%$ & 106 & -0.02 & -0.03 \\
\hline $6.5-6.75$ & 591 & 189 & 0.0 & 0.0 & $1.82 \%$ & 95 & 0.06 & 0.06 \\
\hline $6.75-7$ & 437 & 148 & -0.5 & 0.0 & $1.46 \%$ & 106 & 0.03 & 0.04 \\
\hline $7-7.25$ & 551 & 162 & -1.0 & -0.1 & $1.82 \%$ & 99 & -0.19 & -0.19 \\
\hline $7.25-7.5$ & 592 & 162 & -0.9 & -0.1 & $2.55 \%$ & 101 & -0.04 & -0.04 \\
\hline $7.5-8$ & 611 & 126 & -2.8 & -0.2 & $1.09 \%$ & 101 & -0.07 & -0.07 \\
\hline $8-8.5$ & 717 & 118 & -3.8 & -0.2 & $2.37 \%$ & 95 & -0.07 & -0.10 \\
\hline $8.5-9$ & 326 & 73 & -6.1 & -0.4 & $0.18 \%$ & 89 & -0.20 & -0.19 \\
\hline \multirow[t]{2}{*}{$>9$} & 565 & 55 & -7.1 & -0.5 & $0.91 \%$ & 92 & -0.08 & -0.09 \\
\hline & $\overline{16,783}$ & 274 & & & & & & \\
\hline
\end{tabular}

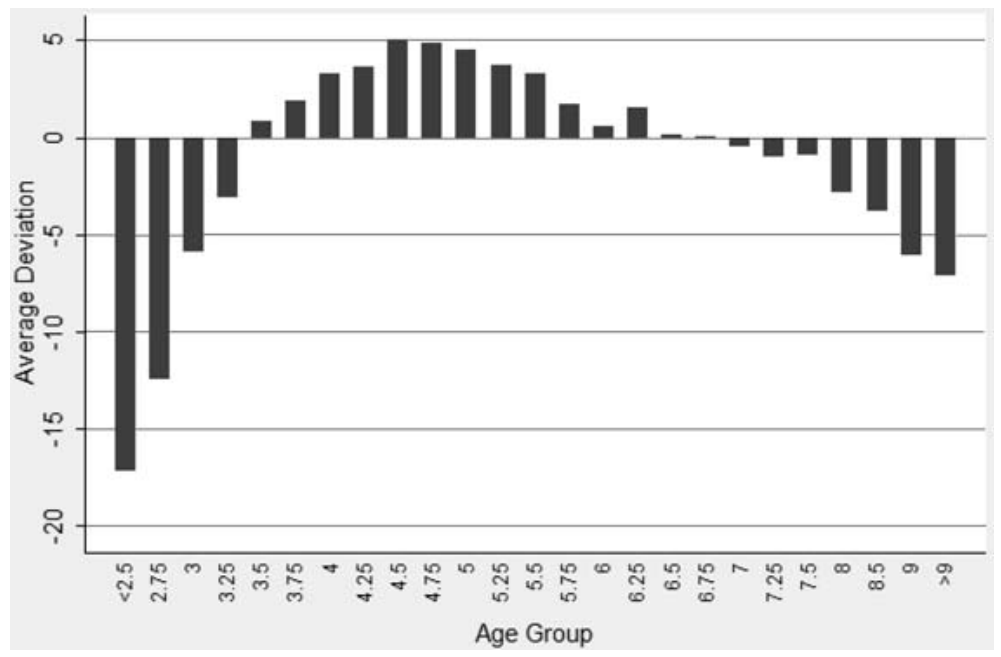

Fig. 1. Deviation from mean speed figure by age.

run an average 7.1 points slower than their career mean and 12.1 points slower than the peak age category. According to the table, horses improve by 22.2 points as young two-year-olds to the middle part of their four- year-old year and then decline by 12.1 points over the next five years. In sprint races this translates to a 9 length improvement to the peak and a 5 length decline. In route races it is a $131 / 2$ length improvement to peak 
Table 5. Regression Estimates

\begin{tabular}{|c|c|c|}
\hline & Coef. & SE \\
\hline gamma 1 & -4.584 & 0.127 \\
\hline gamma 2 & -0.578 & 0.021 \\
\hline delta & \multicolumn{2}{|c|}{4.45} \\
\hline obs & \multicolumn{2}{|c|}{16,783} \\
\hline horses & \multicolumn{2}{|c|}{274} \\
\hline Age & $\mathrm{R}_{\mathrm{k}}$ & $D_{k}$ \\
\hline 2 & -26.32 & 37.43 \\
\hline 3 & -9.09 & 21.70 \\
\hline 4 & -1.02 & 5.98 \\
\hline 5 & -0.58 & -1.23 \\
\hline 6 & -1.87 & -3.21 \\
\hline 7 & -4.32 & -5.20 \\
\hline 8 & -7.93 & -7.18 \\
\hline
\end{tabular}

and a $71 / 2$ length decline. Pct High SF is the percentage of horses that earned their career highest speed figure when they were the age of the corresponding category. Just over $3 \%$ of the sample earned their best figure as a two-year-old. This increases to $23.1 \%$ as a three-yearold, $32.9 \%$ as a four-year-old, and $21.2 \%$ as a five-yearold. $80 \%$ of all horses in the sample earned their top speed figure below the age of six. Three horses earned their top speed figure as nine-year-olds: Sunshine Bear ran a 91 , winning by 14 lengths at 9.3 years of age, Messenger Springs earned a 73 to win by a length at 9.46 years of age, and My Friend Jim ran a 63 at 9.94 years of age. Highest Speed Figure is the best figure run in the corresponding age category.

The effect of age on racing distance is studied by looking at the difference and standard difference between the distance of a specific race and the mean distance of all races that the horse competed in. There is a large increase in racing distance over the course of a horse's two- year-old year. In the spring of the twoyear-old year, horses compete in short sprint races between $4 \frac{1}{2}$ furlongs and 6 furlongs. Typically a twoyear-old will not run a route race ( 8 furlongs or longer) until the fall. Therefore, horses less than 21/2 years old have the smallest average distance run by a significant margin. Horses in this category run 0.75 furlongs less in distance than their career average.

Table 5 presents the regression estimates of equation (2). $R_{k}$ is the difference between the predicted speed figure at age $k$ and the predicted speed figure at the peak performance age $\delta . D_{k}$ is the approximate percentage change in speed figure for a horse at age $k$.

\section{Predicted Speed Figure by Age}

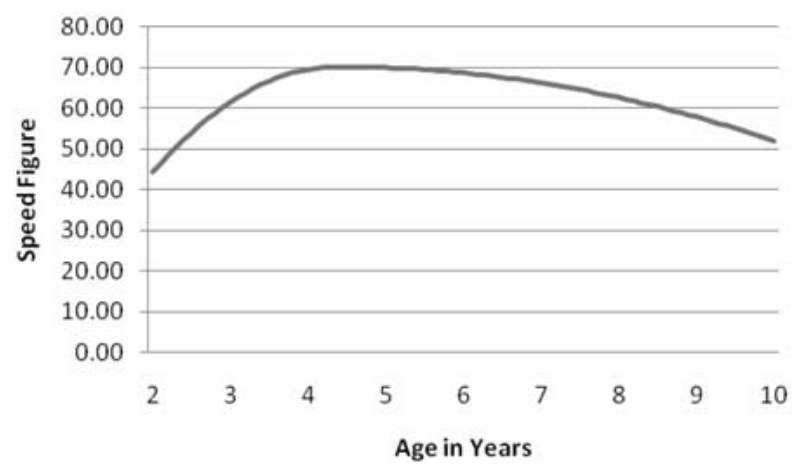

Fig. 2. Predicted speed figure by age.

$$
\begin{aligned}
& R_{k}=\hat{y}_{i t}\left|\left(x_{i t}=k\right)-\hat{y}_{i s}\right|\left(x_{i s}=\hat{\delta}\right) \\
& D_{k}=100 \quad \frac{\left(\partial y_{i t} / \partial x_{i t}\right) \mid\left(x_{i t}=k\right)}{\bar{y}}
\end{aligned}
$$

Peak age is estimated to be 4.45 years. At age 2 a horse is predicted to be 26 points slower than at peak age. The improvement over the first two years is dramatic and the subsequent decline is more gradual. Predicted speed figure by age for the mean ability horse is depicted in Fig. 2.

\section{References}

1. Baker, J., Deakin, J., Horton, S., and Pearce, G.W. 2007. Maintenance of skilled performance with age: a descriptive examination of professional golfers. J. Aging Phys. Act. 15: 300-317.

2. Beyer, A. 1993. Beyer on Speed. Houghton Mifflin, New York.

3. Bailey, C.J., Reid, S.W.J., Hodgson, D.R., and Rose, R.J. 1999. Impact of injuries and disease on a cohort of two- and three-year-old thoroughbreds in training. Vet. Rec. 145: 487-493.

4. Bradbury, J.C. 2008. Peak athletic performance and ageing: evidence from baseball. J. Sports Sci. 27: 599-610.

5. Brown-Douglas, C.G., Pagan, J.D., and Stromberg, A.J. 2006. Thoroughbred growth and future racing performance. Proc. Kentucky Equine Res. Nutr. Conf. 15: 16-29.

6. Fair, R.C. 1994. How fast do old men slow down? Rev. of Econ. and Stat. 76: 103-118.

7. Fair, R.C. 2006. Estimated age effects in athletic 
events and chess. Cowles Foundation Discussion Papers: 1536, Cowles Foundation, Yale University, New Haven.

8. Fair, R.C. 2008. Estimated age effects in baseball. J. of Quan. Anal. in Sports 4: 1-39.

9. Green, D.A. 1969. A study of growth rate in Thoroughbred foals. British Vet. J. 125: 539-546.

10. Hintz, H.F., Hintz, R.L., and Van Vleck, L.D. 1979. Growth rate of Thoroughbreds: effect of age of dam, year and month of birth, and sex of foal. J. of Anim. Sci. 48: 480-487.

11. McCarthy, D., and Mitchell, J. 1974. A study of growth rate in Thoroughbred foals and yearlings. Irish J. of Ag. Res. 13: 111-117.
12. More, S.J. 1999. A longitudinal study of racing Thoroughbreds: performance during the first years of racing. Aust. Vet. J. 77: 105-112.

13. Over, R., and Thomas, P. 1995. Age and skilled psychomotor performance: a comparison of younger and older golfers. Int. J. Aging Hum. Dev. 41: 1-12.

14. Sobczyńska, M. 2007. The effect of selected factors on length of racing career in Thoroughbred racehorses in Poland. Anim. Sci. Papers and Reports, 25: 131-141.

15. Thompson, K.N. 1995. Skeletal growth rates in weanling and yearling Thoroughbred horses. $J$. Anim. Sci. 73: 2513-2517. 